\title{
Comparison of Elasto-Mechanical Behavior of Rubbers
}

\author{
Burak Yenigun $^{1 *}$, E. Gkouti ${ }^{1}$, A. Czekanski ${ }^{1}$, G. Barbaraci ${ }^{1}$, K.P. Jankowski ${ }^{2}$, \\ ${ }^{1}$ Department of Mechanical Engineering, York University, Toronto, Canada \\ ${ }^{2}$ Magna Closures of America Inc., Troy, MI, USA \\ byenigun@yorku.ca, **alex.czekanski@lassonde.yorku.ca
}

\begin{abstract}
This study aims to experimentally compare the elasto-mechanical behaviors of ethylene propylene diene monomer rubber (EPDM), neoprene rubber, silicone rubber, and natural rubber. Rubbers were tested under uniaxial, equibiaxial, and planar loading for five different samples of each material, and the average values have been calculated. Based on the experimental results, a rubber identification was performed by using different rubber models such as Ogden, Mooney-Rivlin, etc. presented in the literature. The result of this study demonstrated that the EPDM rubber showed the highest stress value compared to the other rubbers, silicone rubber, and natural rubber showed similar behavior. Moreover, Neoprene rubber showed the lowest stress value.
\end{abstract}

\section{Keywords; Rubber; Nonlinear; Hyperelastic material}

\section{INTRODUCTION}

Rubbers are widely used in military, food, automotive, and medicine due to their convenient mechanical behavior [1]. The main applications consist of tires, seals, gaskets, shock and vibration absorbers, medical devices, and electrical insulators [1-3]. Rubbers usually demonstrate an incompressible hyperelastic behavior [5]. Rubbers undergo large deformations under relatively small stresses and then return to their initial position, without any remaining deformation. The stress-strain relation is not linear, and so it can be defined using the strain energy function, which is calculated by several existing theoretical models [6-10], such as Polynomial, Ogden, Mooney-Rivlin, Arruda Boyce, etc. To define the strain energy function of rubber, it is necessary to know the behaviors of rubber under different stresses. To determine the coefficients of the strain energy function, uniaxial, planar, and equibiaxial tests are generally performed. This study aims to the experimental comparison of elasto-mechanical behavior of EPDM, natural rubber, silicone rubber, and neoprene rubber, and the identification of elasto-mechanical properties of different rubbers using the theoretical models in ABAQUS.

\section{MATERIALS AND MethodS}

\section{A. Material}

EPDM, neoprene rubber, silicone rubber, and natural rubbers, which are used frequently in engineering applications and which are easy to supply, were used in this study,. The dimension of samples in uniaxial, equibiaxial, and planar tests are shown in Fig. 1.

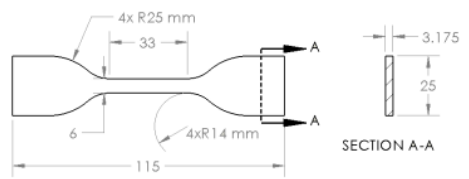

a) Uniaxial sample

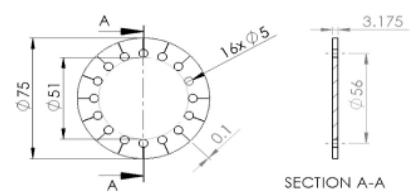

b) Equibiaxial sample

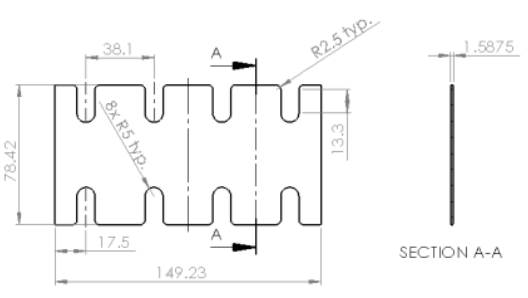

c) Planar sample

Figure 1. The dimensions of samples

\section{B. Experimental Setup}

The experiments have been conducted in a quasi-static strain rate with a crosshead moving at $1 \mathrm{~mm} / \mathrm{s}$, with a sampling rate of $5 \mathrm{~Hz}$ at constant room temperature. The strains were measured by laser extensometer during the tests. The experimental data have been carried out from a set of five samples. The experimental setups are shown in Fig. 2. 


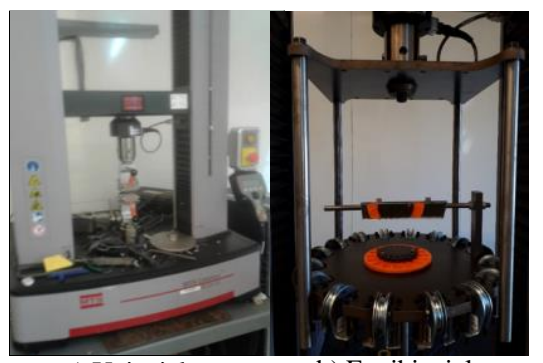

a) Uniaxial

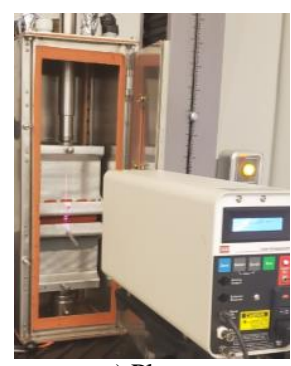

c) Planar
Figure 2. Experimental setups

\section{EXPERIMENTAL RESULTS}

\section{A. Experimental Comparison of Rubbers}

During the uniaxial test, the highest stress values reached belong to the EPDM rubber, followed by silicone rubber, natural rubber, and neoprene rubber in Fig. 3. All the rubbers involved in the uniaxial experiment exhibit similar deformation values before failure. The EPDM exhibits an initial slope, which is the highest compared to the other rubbers, while silicone rubber and natural rubber exhibit a similar mechanical behavior even if the molecular compounds characterizing these two polymers are different.

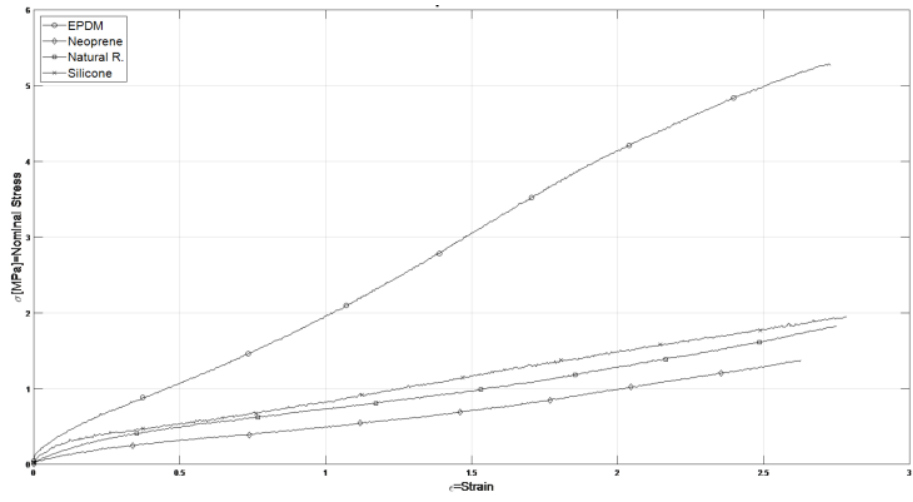

Figure 3. Comparison of uniaxial test results of rubbers

When the equibiaxial test compared, it has been observed that the EPDM reached the highest value of stress in Fig. 4. In the same figure, it is possible to see how not all rubbers reach the same strain; some of them stop before to exhibit the second inflection point.

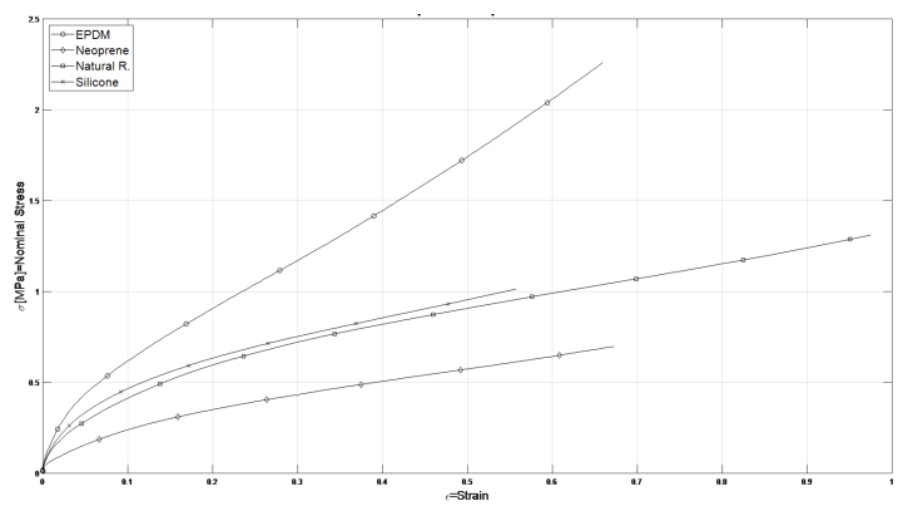

Figure 4. Comparison of equibiaxial test results of rubbers
In Fig. 5, it is possible to see how the EPDM exhibits the highest value of stress as the neoprene rubber and, at the same time, the smallest deformation followed by neoprene rubber, natural rubber, and silicone rubber for the planar test. These different characteristics lead to a different selection of the rubber that must perform a specific job.

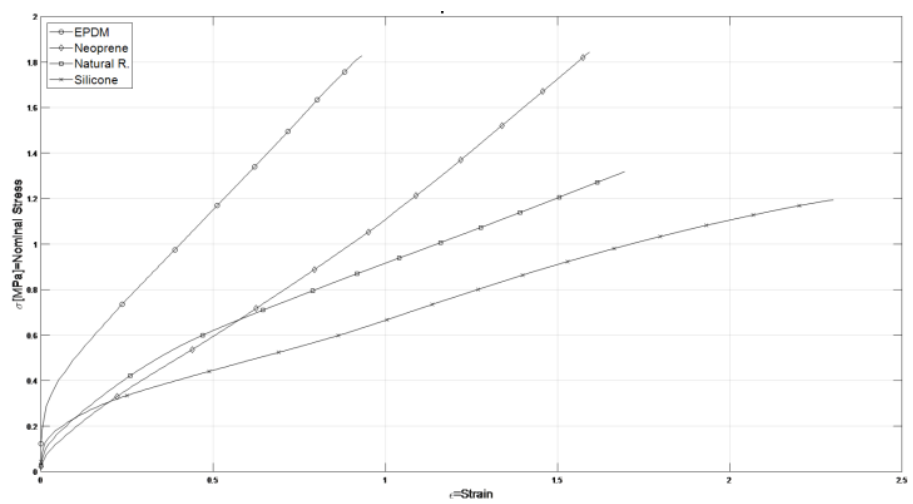

Figure 5. Comparison of planar test results of rubbers

\section{B. Identification of Rubbers}

The comparisons of different theoretical models for uniaxial test data, planar test data, and equibiaxial test data using ABAQUS are shown in Fig.6, Fig. 7, and Fig.8, respectively. In the same figures, it is possible to see how by increasing the polynomial degree, $\mathrm{N}$, the fitting error decreases as shown. The identification process with the models obtained by using ABAQUS $®$ reveals that by increasing the degree of the polynomial used to approximates the value, the fitting error decreases. The general conclusion could not be said for the rubbers; different models demonstrate different results for different rubbers. The best theoretical model for:

Uniaxial tests: Reduced Polynomial $\mathrm{N}=5$, Ogden $\mathrm{N}=3$, Ogden $\mathrm{N}=4$, and Reduced Polynomial $\mathrm{N}=5$ for EPDM, neoprene rubber, natural rubber, and silicone rubber, respectively.

Planar tests: Reduced Polynomial N=5, Polynomial $\mathrm{N}=1$, Ogden $\mathrm{N}=2$, and Reduced Polynomial $\mathrm{N}=5$ for EPDM, neoprene rubber, natural rubber, and silicone rubber, respectively.

Equibiaxial tests: Ogden $\mathrm{N}=4$, Ogden $\mathrm{N}=1$, Ogden $\mathrm{N}=4$, and Reduced Polynomial $\mathrm{N}=5$ for EPDM, neoprene rubber, natural rubber, and silicone rubber, respectively.

Reduced polynomial $\mathrm{N}=5$ can be offered for the modeling of the hyperplastic behavior of EPDM and silicone rubber. Ogden $\mathrm{N}=3$, Ogden $\mathrm{N}=4$, can be offered for the modeling of hyperplastic behavior of neoprene rubber and natural rubber, respectively. 


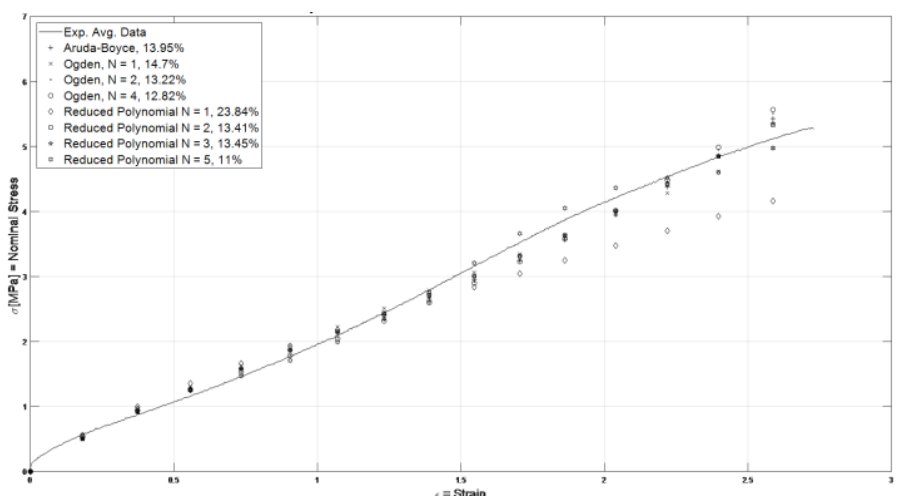

a) EPDM

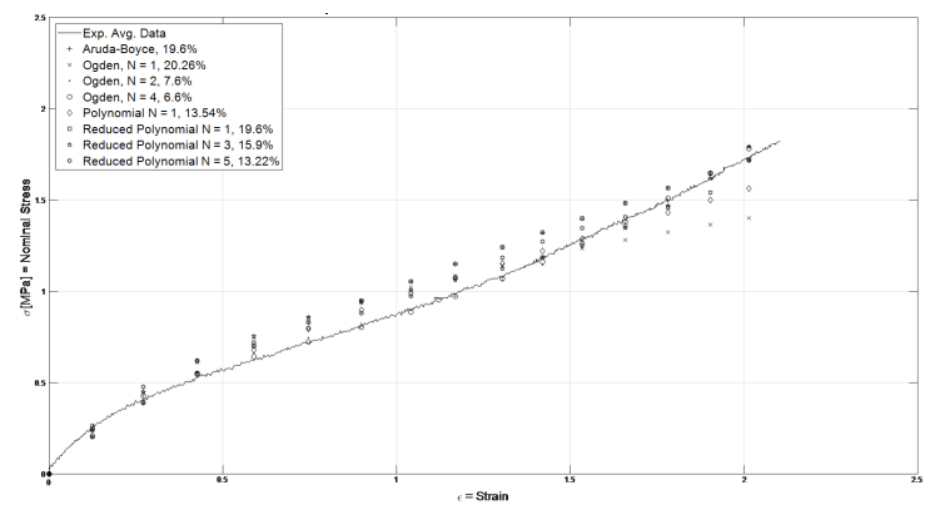

c) Natural rubber

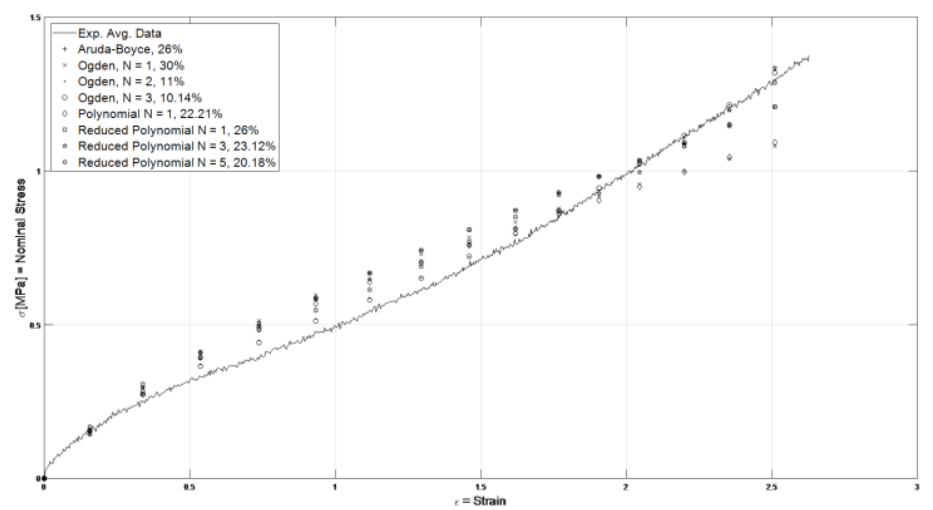

b) Neoprene rubber

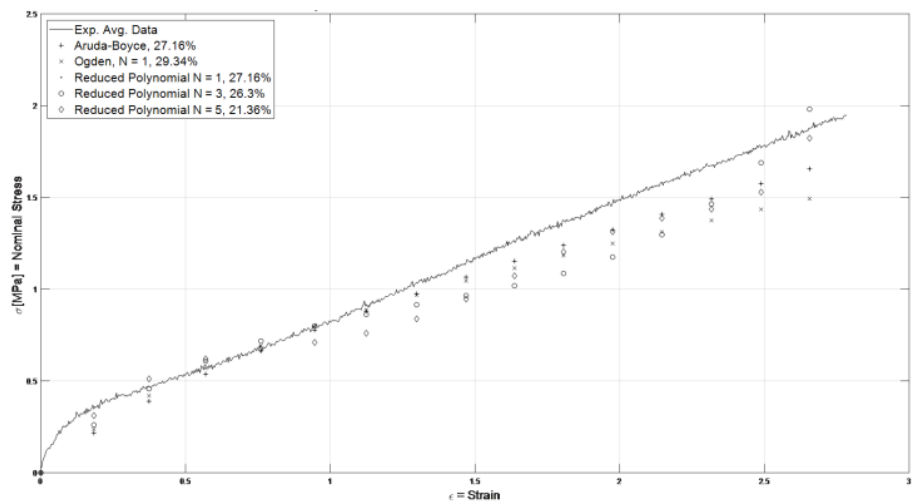

d) Silicone rubber

Figure. 6. Comparison of uniaxial experimental data and theoretical models for rubbers

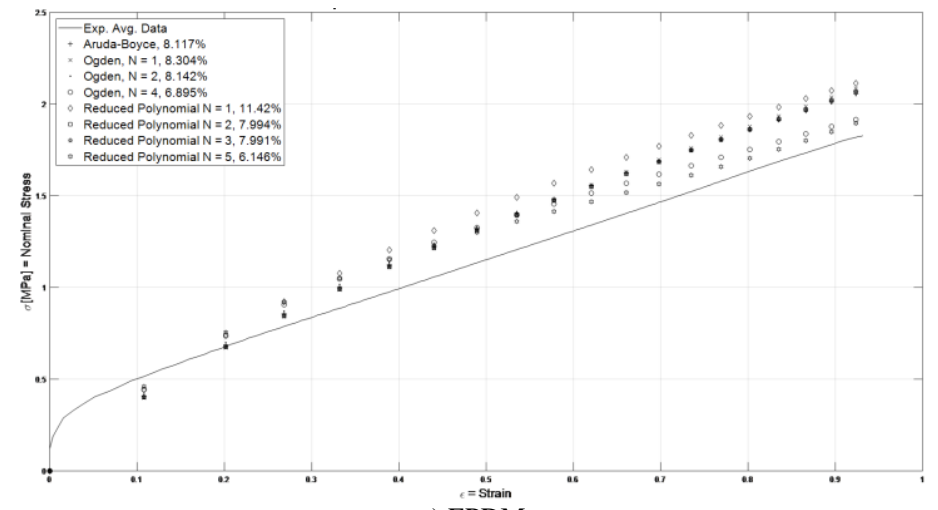

a) EPDM

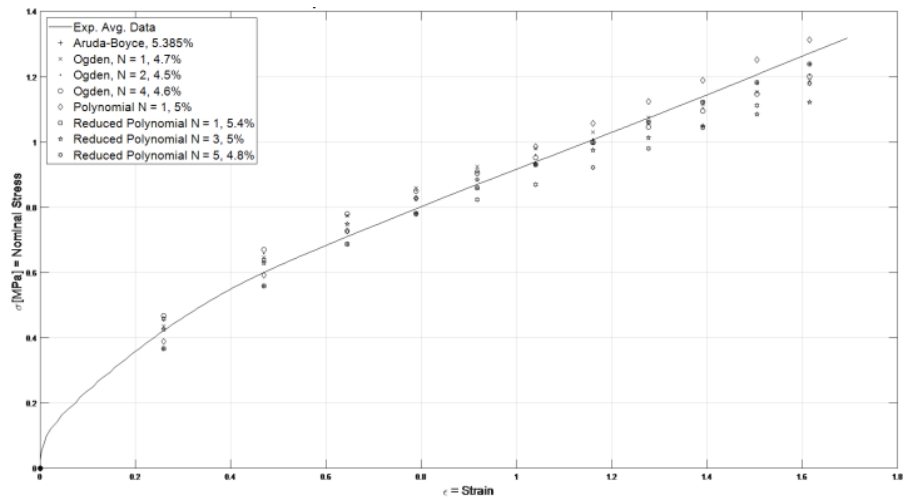

c) Natural rubber

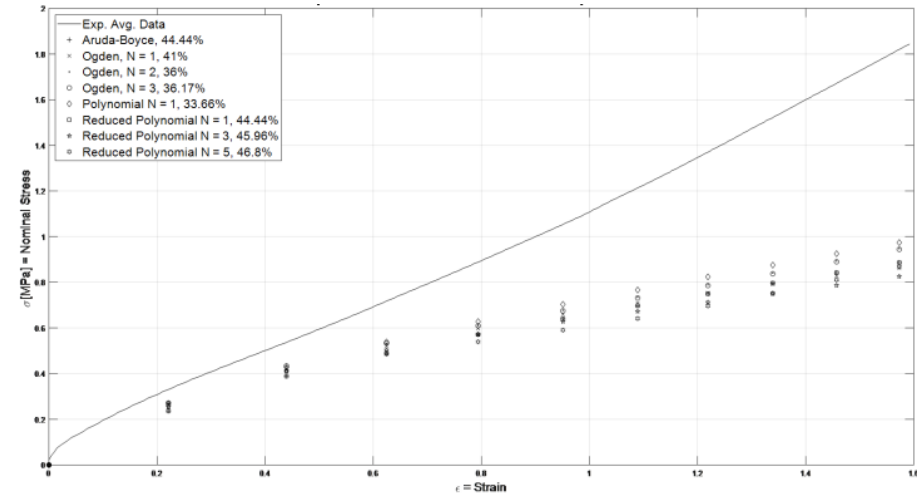

b) Neoprene rubber

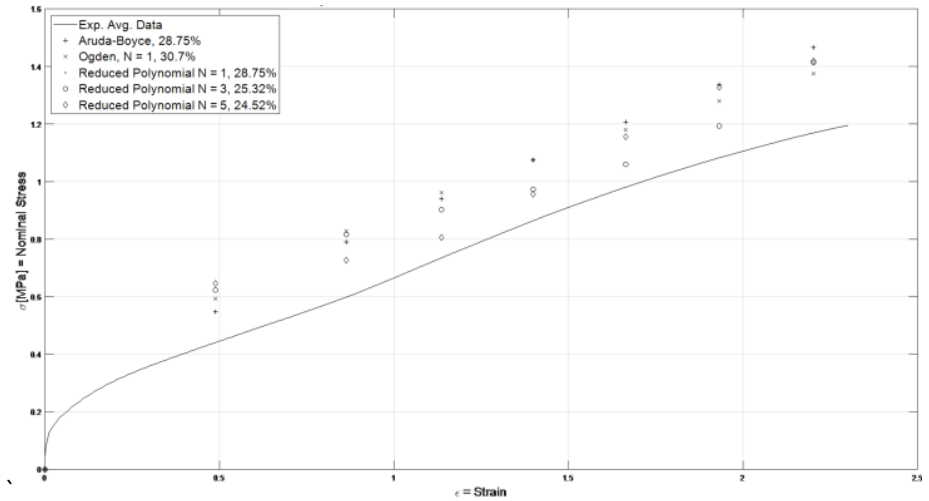

d) Silicone rubber

Figure 7. Comparison of planar experimental data and theoretical models for rubbers 


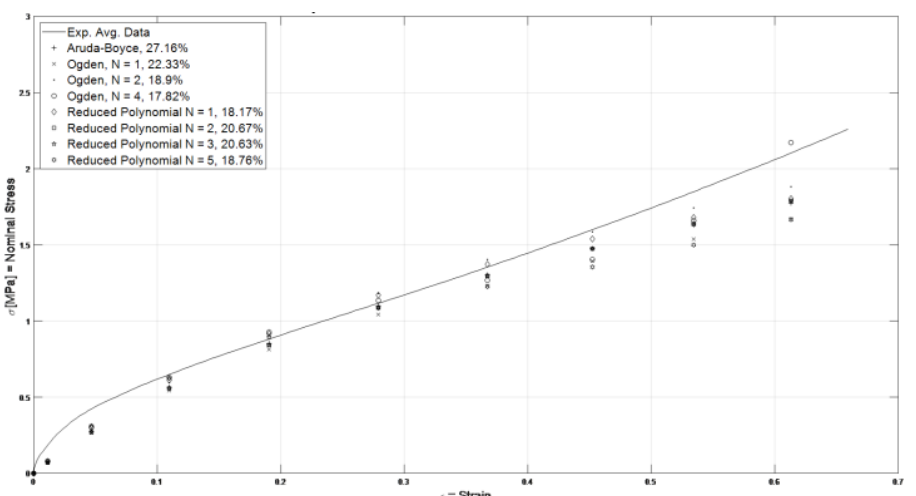

a) EPDM

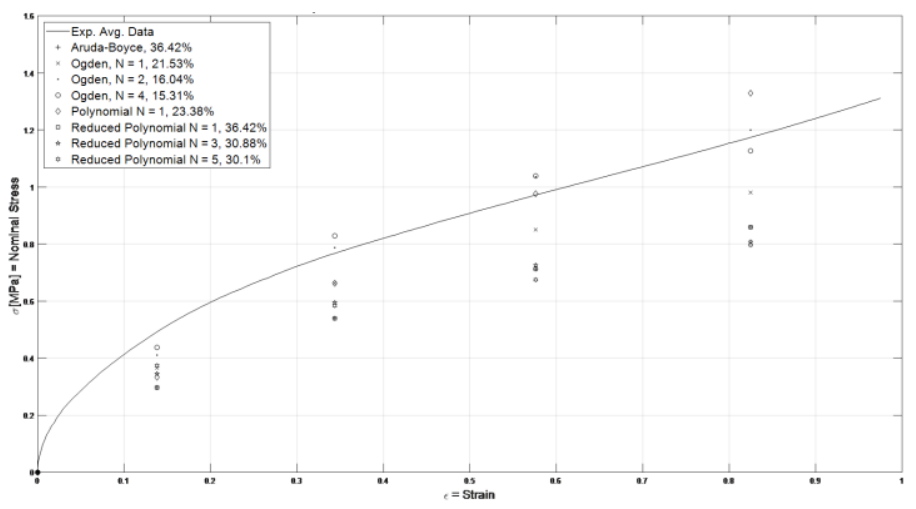

c) Natural rubber

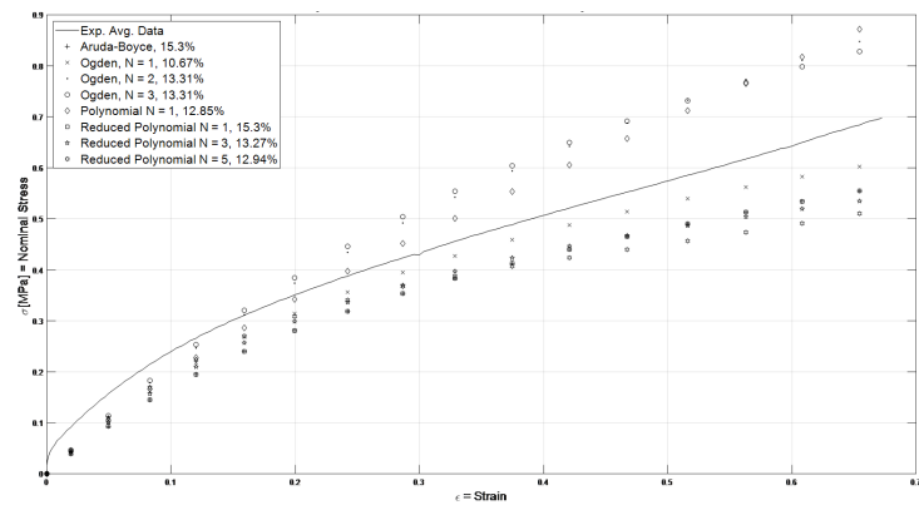

b) Neoprene rubber

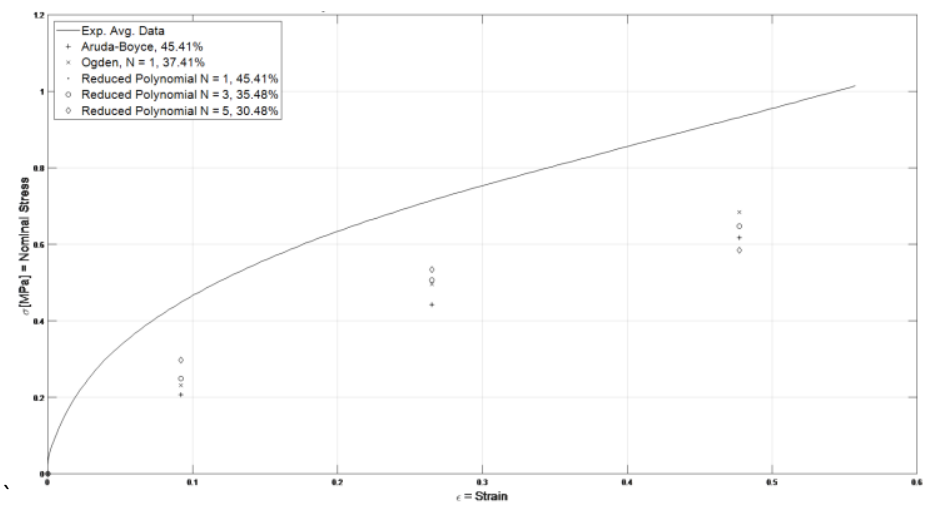

d) Silicone rubber

Figure 8. Comparison of equibiaxial experimental data and theoretical models for rubbers

\section{CONCLISIONS}

In the present work, four different rubbers have been considered to perform the uniaxial, equibiaxial, and planar experiments. The EPDM rubber has revealed the highest stress value compared to the other rubbers, while silicone and natural rubber showed similar behavior. Neoprene rubber is a very soft material compared to other rubbers analyzed in this paper. The ABAQUS® implementation has been developed according to the average value carried out from the experimental data from where have been obtained the all the stable models representing the experimental data from the rubber tests. The stable models that best represent the rubber analyzed in this work are, Ogden, and reduced polynomial $\mathrm{N}=5$. All these models exhibit a certain fitting error percentage that clarifies the accuracy of that model in representing the experimental data. One can see that the fitting error decreases by increasing the polynomial degree. It cannot be claimed that the existing theoretical models in the Abaqus program are successful. Instead, it is recommended to use the new introduced constitutive models in the literature using subroutines to elasto-mechanical behavior of rubbers.

\section{REFERENCES}

[1] W. Wu and H. Huang, "Silicone rubber composites fabricated using KH550-modified poplar leaves graphene," Bull. Mater. Sci., vol. 43, no. $1,2020$.
[2] R. Rugsaj and C. Suvanjumrat, "Finite element analysis of hyperelastic material model for non-pneumatic tire," in Key Engineering Materials, 2018.

[3] C. Cheng, S. Li, Y. Wang, and X. Jiang, "Force and displacement transmissibility of a quasi-zero stiffness vibration isolator with geometric nonlinear damping," Nonlinear Dyn., 2017.

[4] L. P. Li, "Experiment analysis about mechanical properties of rubber bushing for suspension telescopic shock absorber," in Applied Mechanics and Materials, 2014.

[5] Z. Zhao, X. Mu, and F. Du, "Modeling and Verification of a New Hyperelastic Model for Rubber-Like Materials," Math. Probl. Eng., 2019.

[6] M. Mooney, "A theory of large elastic deformation," J. Appl. Phys., 1940.

[7] L. R. G. Treloar, "Strains in an Inflated Rubber Sheet, and the Mechanism of Bursting," Rubber Chem. Technol., 1944.

[8] "Large elastic deformations of isotropic materials IV. further developments of the general theory," Philos. Trans. R. Soc. London. Ser. A, Math. Phys. Sci., 1948.

[9] L. R. G. Treloar, "MECHANICS OF RUBBER ELASTICITY.," Proc $R$ Soc London Ser A, 1976.

[10] "Large deformation isotropic elasticity - on the correlation of theory and experiment for incompressible rubberlike solids," Proc. R. Soc. London. A. Math. Phys. Sci., 1972. 
